\title{
UTSA-74: An Isomeric MOF-74 with Two Accessible Binding Sites per Metal Center for Highly Selective Gas Separation
}

Feng Luo, Changsheng Yan, Lilong Dang, Rajamani Krishna, Wei Zhou, Xinglong Dong, Yu Han, Tong-Liang Hu, Michael O’Keeffe, Lingling Wang, Mingbiao Luo, Rui-Biao Lin, Banglin Chen*

Table S1. Crystallographic data of UTSA-74, UTSA-74a, and UTSA-74つCO

\begin{tabular}{|c|c|c|c|}
\hline Compounds & UTSA-74 & UTSA-74a & UTSA-74دCO \\
\hline Empirical formula & $\mathrm{C}_{24} \mathrm{H}_{12} \mathrm{O}_{21} \mathrm{Zn}_{6}$ & $\mathrm{C}_{24} \mathrm{H}_{6} \mathrm{O}_{18} \mathrm{Zn}_{6}$ & $\mathrm{C}_{27} \mathrm{H}_{6} \mathrm{O}_{24} \mathrm{Zn}_{6}$ \\
\hline Formula weight & 1028.79 & 974.51 & 1106.54 \\
\hline Temperature (K) & $296(2)$ & $296(2)$ & $120(2)$ \\
\hline Wavelength $(\AA)$ & 0.71073 & 0.71073 & 0.71073 \\
\hline Crystal system, space group & Rhombohedral, R-3c & Rhombohedral, R-3c & Rhombohedral, R-3c \\
\hline Unit cell dimensions $(\AA)$ & $\mathrm{a}=\mathrm{b}=22.9170(4), \mathrm{c}=15.9024(5)$ & $\mathrm{a}=\mathrm{b}=22.9556(13), \mathrm{c}=15.883(2)$ & $\begin{array}{l}\mathrm{a}=\mathrm{b}=22.9511(8) \\
\mathrm{c}=15.8965(11)\end{array}$ \\
\hline Volume $\left(\AA^{3}\right)$ & $7232.8(3)$ & $7248.2(12)$ & $7251.7(6)$ \\
\hline $\mathrm{Z}$, Calculated density $\left(\mathrm{Mg} / \mathrm{m}^{3}\right)$ & $12, \quad 1.409$ & $6, \quad 1.34$ & $6, \quad 1.52$ \\
\hline $\mathrm{F}(000)$ & 2988 & 2844 & 3240 \\
\hline Crystal size $(\mathrm{mm})$ & $0.18 \times 0.08 \times 0.08$ & $0.18 \times 0.08 \times 0.08$ & $0.18 \times 0.08 \times 0.08$ \\
\hline Theta range for data collection & $2.76-27.51$ & $2.76-26.00$ & $2.42-27.64$ \\
\hline Completeness to theta & $99.6 \%$ & $99.6 \%$ & $97.3 \%$ \\
\hline GOF & 1.215 & 0.915 & 1.282 \\
\hline Final $R$ indices [I>2sigma $(\mathrm{I})]$ & $\mathrm{R}_{1}=0.0772, \omega \mathrm{R}_{2}=0.1717$ & $\mathrm{R}_{1}=0.1221, \omega \mathrm{R}_{2}=0.2445$ & $\mathrm{R}_{1}=0.1631, \omega \mathrm{R}_{2}=0.3024$ \\
\hline
\end{tabular}

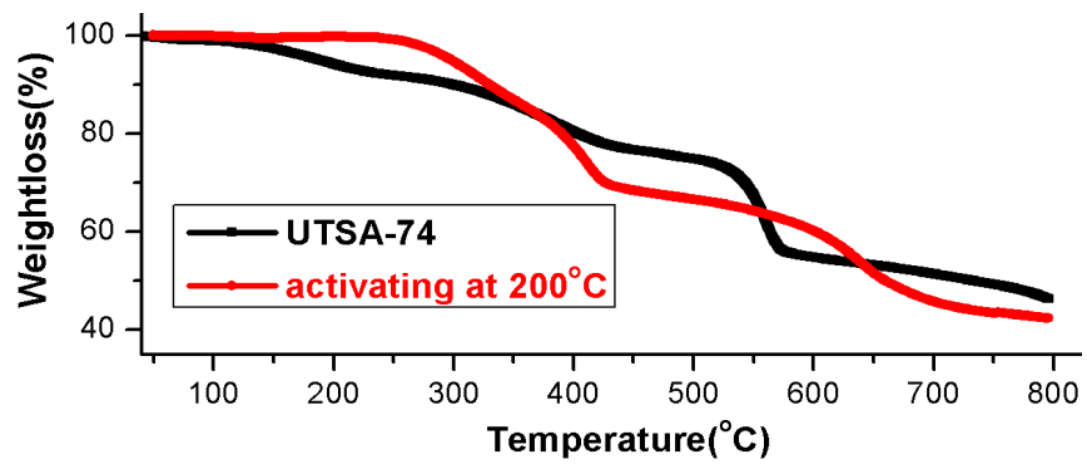

Figure S1. The TG plots of as-synthesized samples and activated samples of UTSA-74. 


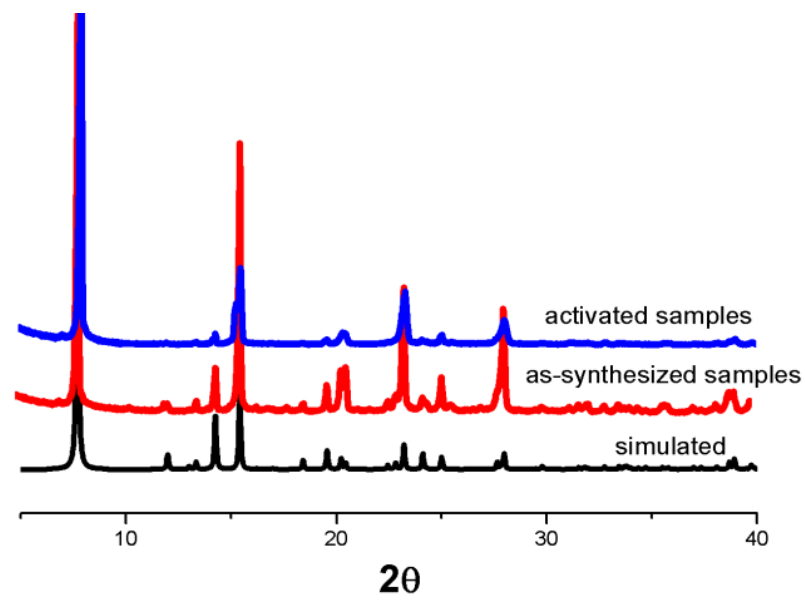

Figure S2. The PXRD patterns of as-synthesized and activated samples of UTSA-74, as well as the simulated PXRD patterns calculated from the single crystal data of UTSA-74.

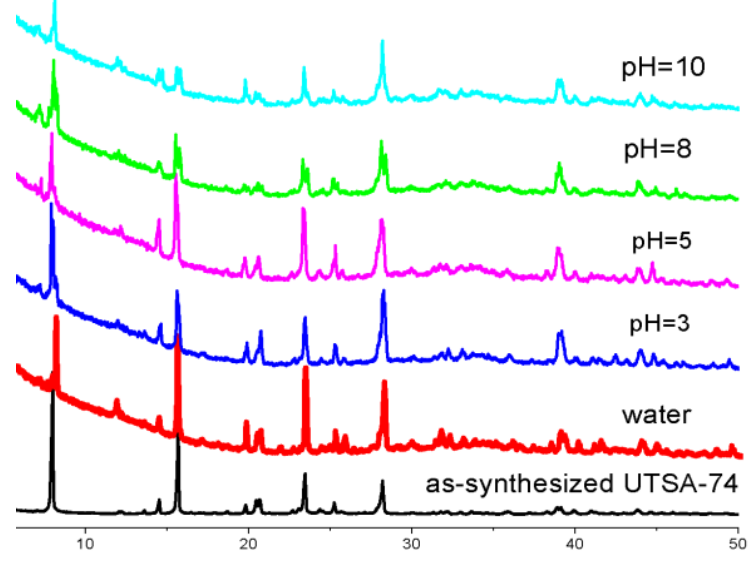

$2 \theta$

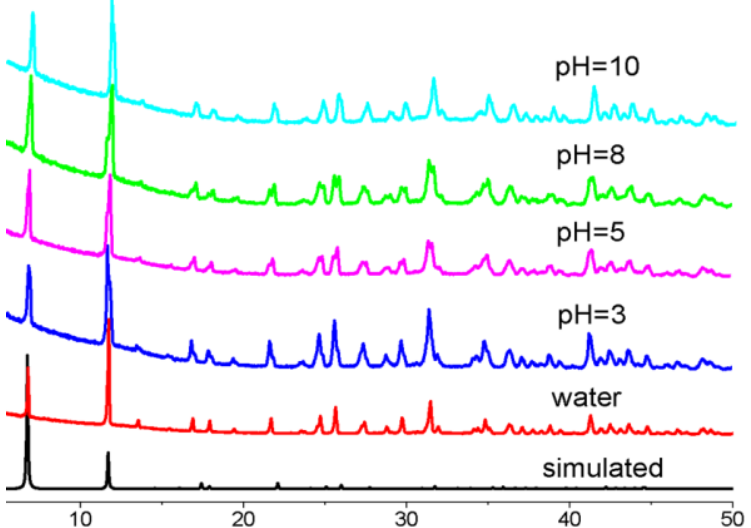

$2 \theta$

Figure S3. The PXRD patterns of UTSA-74 and Zn-MOF-74 after immerging in water with the pH values in the range of 3 to 10 for 24 h, respectively (UTSA-74 (left); Zn-MOF-74 (right)).
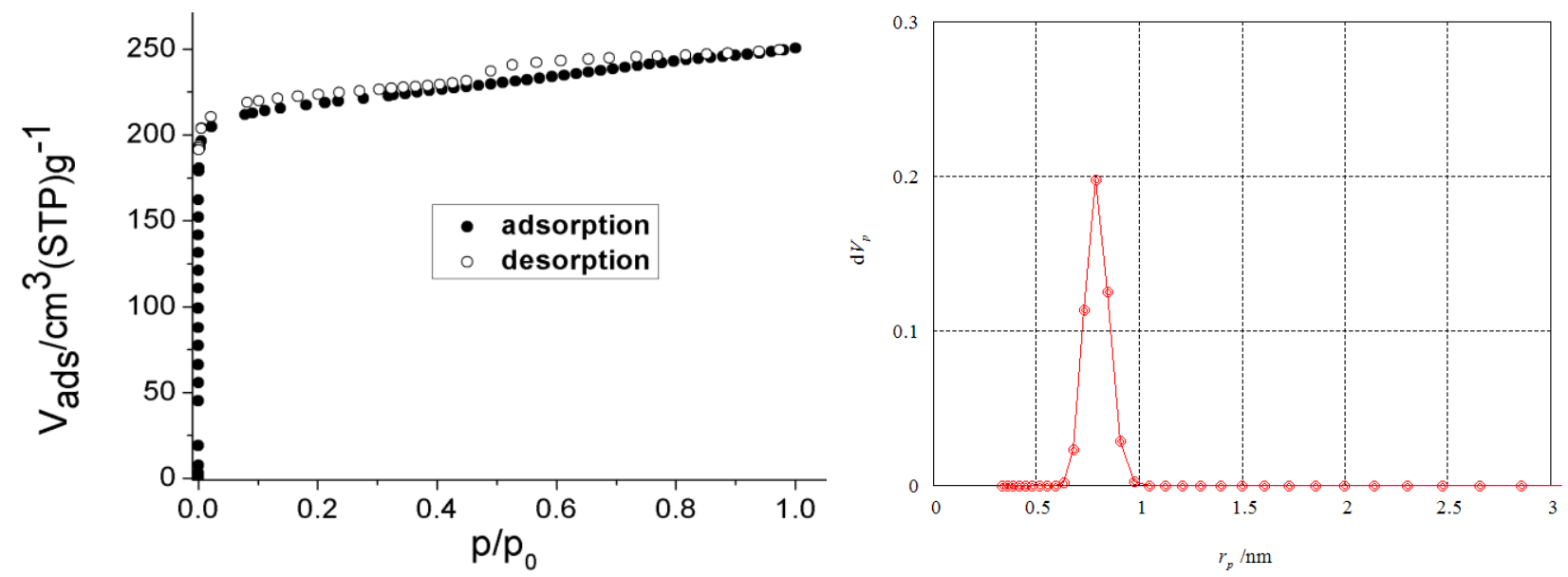

Figure S4. The $\mathrm{N}_{2}$ adsorption isotherms at $77 \mathrm{~K}$ and the pore distribution of UTSA-74a. 

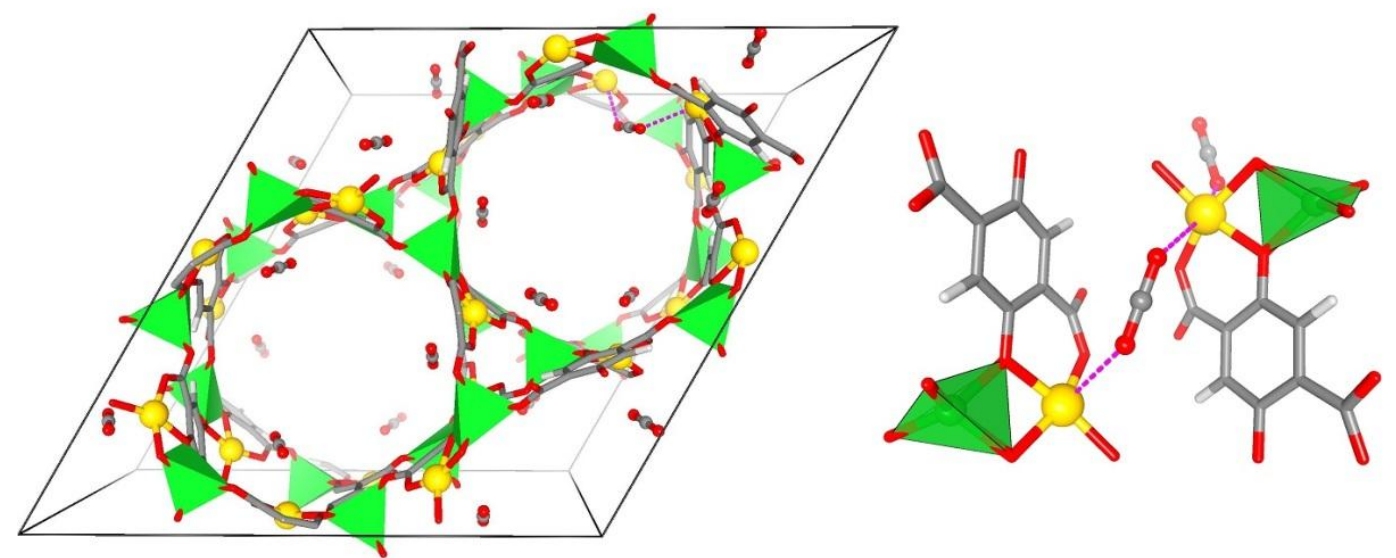

Figure S5. The DFT-D optimized structure of UTSA-74 $\supset \mathbf{C O}_{2}$ in which the local coordination environments are shown at the right.

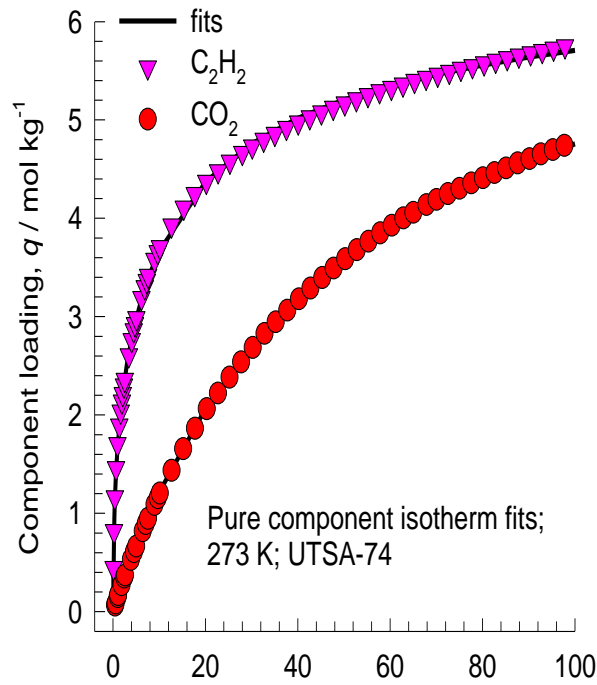

Bulk gas phase pressure, $\mathrm{p} / \mathrm{kPa}$

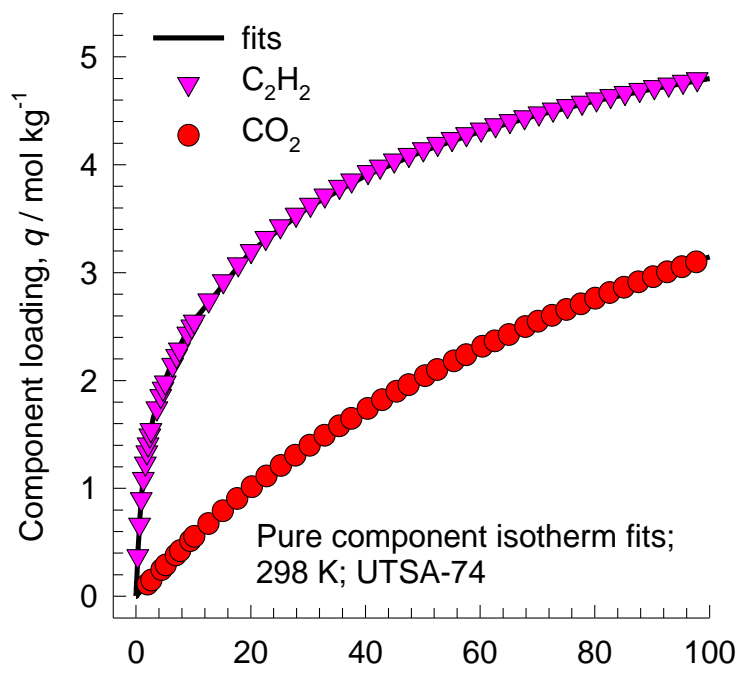

Bulk gas phase pressure, $p / k P a$

Figure S6. Comparison of absolute component loadings for $\mathrm{C}_{2} \mathrm{H}_{2}$, and $\mathrm{CO}_{2}$ at (a) $273 \mathrm{~K}$, and (b) $298 \mathrm{~K}$ in UTSA-74a with the isotherm fits. The experimentally measured excess loadings for $\mathrm{C}_{2} \mathrm{H}_{2}$, and $\mathrm{CO}_{2}$ at temperatures of $273 \mathrm{~K}$, and $298 \mathrm{~K}$ in UTSA-74a were fitted with the dual-Langmuir-Freundlich isotherm model

$$
q=q_{A, s a t} \frac{b_{A} p^{v_{A}}}{1+b_{A} p^{v_{A}}}+q_{B, s a t} \frac{b_{B} p^{v_{B}}}{1+b_{B} p^{v_{B}}}
$$

with $T$-dependent parameters $b_{\mathrm{A}}$, and $b_{\mathrm{B}}$

$$
b_{A}=b_{A 0} \exp \left(\frac{E_{A}}{R T}\right) ; \quad b_{B}=b_{B 0} \exp \left(\frac{E_{B}}{R T}\right)
$$

The parameters are provided in Table S2.

Table S2. Dual-Langmuir-Freundlich parameter fits for $\mathrm{C}_{2} \mathrm{H}_{2}$, and $\mathrm{CO}_{2}$ in UTSA-74a.

\begin{tabular}{|l|l|l|l|l|l|l|l|l|}
\hline & \multicolumn{2}{|l|}{ Site $\mathrm{A}$} & \multicolumn{3}{l|}{ Site B } \\
\hline & $\begin{array}{l}q_{\mathrm{A}, \text { sat }} \\
\mathrm{mol} \mathrm{kg}\end{array}$ & $b_{\mathrm{A} 0}$ & $\begin{array}{l}E_{\mathrm{A}} \\
\mathrm{kJ} \mathrm{mol}^{-1}\end{array}$ & $\begin{array}{c}\mathrm{A} \\
\text { dimensionless }\end{array}$ & $\begin{array}{l}q_{\mathrm{B}, \text { sat }} \\
\mathrm{mol} \mathrm{kg}^{-1}\end{array}$ & $b_{\mathrm{B} 0}$ & $\begin{array}{l}E_{\mathrm{B}} \\
\mathrm{kJ} \mathrm{mol}^{-1}\end{array}$ & $\begin{array}{c}\mathrm{B} \\
\text { dimensionless }\end{array}$ \\
\hline
\end{tabular}




\begin{tabular}{|l|l|l|l|l|l|l|l|l|}
\hline & & $\mathrm{Pa}^{-v_{i}}$ & & & & $\mathrm{~Pa}^{-v_{i}}$ & & \\
\hline $\mathrm{C}_{2} \mathrm{H}_{2}$ & 0.7 & $1.81 \times 10^{-16}$ & 60.2 & 1.8 & 6.2 & $2.30 \times 10^{-7}$ & 20.7 & 0.66 \\
\hline $\mathrm{CO}_{2}$ & 4.8 & $2.02 \times 10^{-12}$ & 37 & 1 & 2.4 & $5.37 \times 10^{-6}$ & 2 & 1 \\
\hline
\end{tabular}

\section{Isosteric heat of adsorption.}

The binding energies of $\mathrm{C}_{2} \mathrm{H}_{2}$, and $\mathrm{CO}_{2}$ in UTSA-74a are reflected in the isosteric heat of adsorption, $Q_{\mathrm{st}}$, defined as

$$
Q_{s t}=R T^{2}\left(\frac{\partial \ln p}{\partial T}\right)_{q}
$$

These values were determined using the pure component isotherm fits.

\section{IAST calculations of adsorption selectivities.}

In order to establish the feasibility of $\mathrm{C}_{2} \mathrm{H}_{2} / \mathrm{CO}_{2}$ separations we performed calculations using the Ideal Adsorbed Solution Theory (IAST) of Myers and Prausnitz.

Let us determine the adsorption selectivity, $S_{\text {ads }}$, defined for separation of a binary mixture of species $i$ and $j$ by

$$
S_{a d s}=\frac{q_{i} / q_{j}}{p_{i} / p_{j}}
$$

where the $q_{\mathrm{i}}$ represent the molar loadings of component $i$ that is in equilibrium with a bulk gas phase with partial pressures $p_{\mathrm{i}}$ in the mixture.

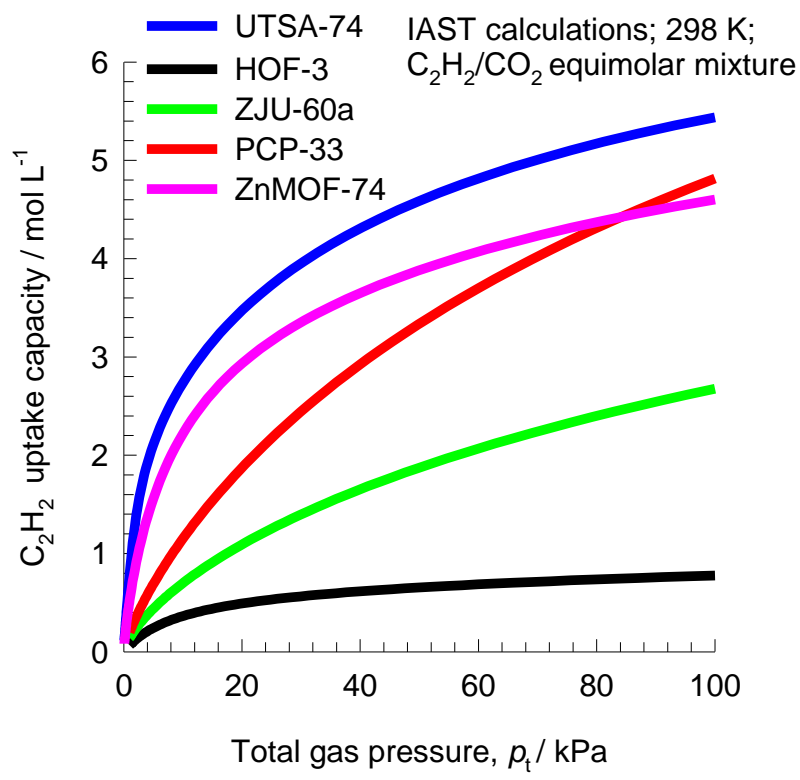

Figure S7. IAST calculations of uptake capacity of $\mathrm{C}_{2} \mathrm{H}_{2}$, for separation of $50 / 50 \mathrm{C}_{2} \mathrm{H}_{2} / \mathrm{CO}_{2}$ mixture at $298 \mathrm{~K}$ using $\mathrm{HOF}-3$,

UTSA-74a, ZJU-60a, and PCP-33.

\section{Transient breakthrough simulations.}

The performance of industrial fixed bed adsorbers is dictated by a combination of adsorption selectivity and uptake capacity. For a proper comparison of various MOFs, we perform transient breakthrough simulations using the simulation methodology described in the literature. For the breakthrough simulations, the following parameter values were used: length of packed bed, $L=0.3 \mathrm{~m}$; voidage of packed bed, $\varepsilon=0.4$; superficial gas velocity at inlet, $u=0.04 \mathrm{~m} / \mathrm{s}$. The framework density of UTSA-74a is $1401 \mathrm{~kg} \mathrm{~m}{ }^{-3}$.

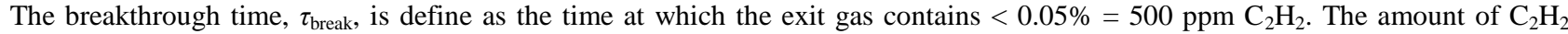
captured during the time interval $0-\tau_{\text {break }}$ can be determined from a material balance. These amounts, expressed as moles $\mathrm{C}_{2} \mathrm{H}_{2}$ 
captured per $\mathrm{L}$ of framework material, are plotted against $\tau_{\text {break }}$ in Table S3.

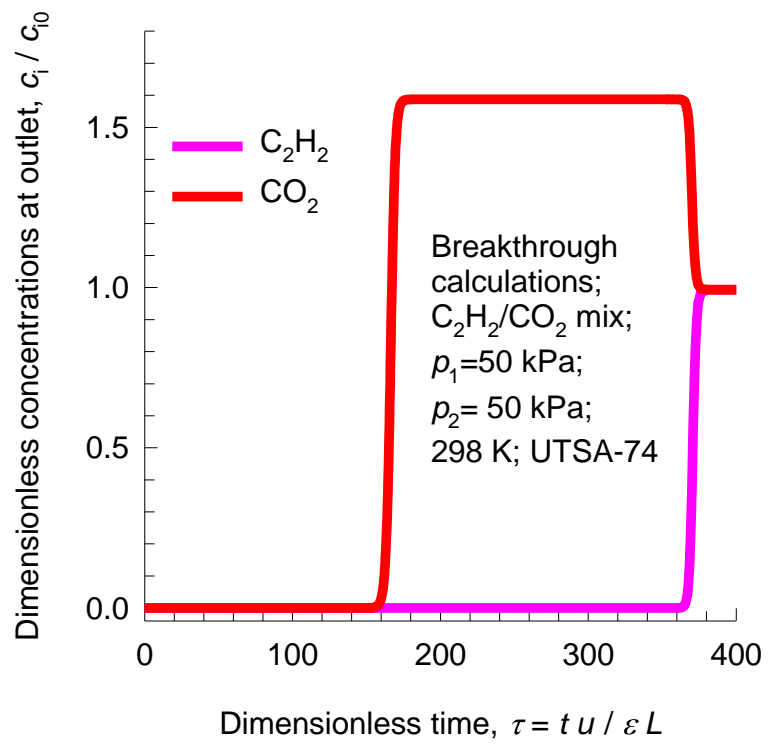

Figure S8. Transient breakthrough simulations for separation of equimolar $\mathrm{C}_{2} \mathrm{H}_{2} / \mathrm{CO}_{2}$ mixture using UTSA-74a at $298 \mathrm{~K}$, with partial pressures of $50 \mathrm{kPa}$ each.

Table S3. Breakthrough calculations for separation of $50 / 50 \mathrm{C}_{2} \mathrm{H}_{2} / \mathrm{CO}_{2}$ mixture at $298 \mathrm{~K}$.

\begin{tabular}{|l|l|l|}
\hline & Dimensionless breakthrough time $\tau_{\text {break }}$ & $\mathrm{C}_{2} \mathrm{H}_{2}$ adsorbed during 0 - $\tau_{\text {break }} \mathrm{mol} \mathrm{L}^{-1}$ \\
\hline UTSA-74a & 362 & 4.86 \\
\hline UTSA-60a & 173 & 2.33 \\
\hline PCP-33 & 308 & 4.16 \\
\hline HOF-3 & 52 & 0.7 \\
\hline ZnMOF-74 & 302 & 4.06 \\
\hline
\end{tabular}

